\title{
AN META-ANALYSIS ON THE EFFECT OF ADAPTIVE HYPERMEDIA LEARNING SYSTEM USING LEARNING STYLE ADAPTOR
}

\author{
Sirui $\mathrm{Wu}$ \\ Faculty of Education, University of British Columbia, 2125 Main Mall Vancouver, BC, V6T 1Z4, Canada
}

\begin{abstract}
The usefulness and limitation of Adaptive Hypermedia Learning System (AHLS) using Learning Style as an adaptor has been long discussed, and many empirical studies show the system can help students increase their academic performance comparing with the traditional classroom learning, but these studies were based on different subjects and participators, thus hard to demonstrate the general effect of this system. This study summarized 13 studies to see whether there is a positive effect of AHLS comparing with the traditional learning in general contexts, and then see whether two factors, Learning Style Theory Choosing and Additional Adaptors, would moderate this effect. The result found that AHLS has a positive effect on student's academic performance, but the moderating effect of two covariate was non-significant. Based on this, the study further gave some suggestions of application AHLS in classroom.
\end{abstract}

\section{KEYWORDS}

Adaptive Hypermedia Learning System, Learning Style, Meta-Analysis

\section{INTRODUCTION}

Learning is a complex process, especially in the context of e-learning. Technology power makes it possible to integrate multiple learning materials and tutoring strategies into one single system, giving learners more choices as well as confusions (Linn, 2003). How to organize these materials and strategies arises to be a primary question for all e-learning systems. Adaptivity can provide a evidential grounds for this. The main differences between an adaptive system and a non-adaptive one is the User Model (UM) (Kahraman, et al., 2010). It is a model to track each learners' interactions with the system, evaluate these information, and then obtain the learner's attributes like their personalities and knowledge levels.

The UM makes the adaptive learning system more personalized according to each learner's traits, but only those traits that influenced students' learning outcome should be included into UM. Among these traits learning style is evidenced to be an important one (Nelson, Dunn, Griggs \& Primavera., 1993). Students prefer to follow the teaching strategies that matched with their learning styles, and students who received a matched learning materials perform better on knowledge retention and academic achievement (Klašnja-Milićević, Vesin, Ivanović \& Budimac, 2011).

Another problem of learning materials organization in an educational system is the order of numerous materials. A reasonable solution for this is the hypermedia. This is a collection of multimedia with non-linear order, so users can skip from one material to another (Tolhurst, 1995). The combination of hypermedia and adaptive algorithm is the basement of adaptive hypermedia learning system (AHLS). Hypermedia provide the content, and adaptive algorithm, which is based on learning style in this study, decides the arrangement of content.

There are a lot of studies find hypermedia learning system with adaption of learning styles works well (Chen\& Macredie, 2002) (Carver, Howard\& Lane, 1999). However, these study were conducted under different situations, based on different learning theories, and some even using more than one adaptors including learning style, thus make it hard to see the efficacy of AHLS using learning style in general. This study conduct a meta-analysis over 13 studies, to find the general effect of AHLS using learning style across several contexts, and then see whether two possible important moderators, learning style theory and additional adaptor, could influence this effect. 


\section{LITERATURE REVIEW}

\subsection{Learning Style Theory}

Learning style was a conception first appeared on 1970s and then get varied due to multiple contexts (Kazu, 2009), but among which there were still some points in common. First, most researchers agreed that learning style is a mental traits, like personality, that varied across individuals. Second, learning style works during the whole process of learning, leading to various learning behaviors and performances. Appendix Table 2 compared 8 main kinds of learning theory.

Table 1 gives a summary for popular learning style theories, comparing their definitions and methods of classification. In general, the main differences across these theories is the classification of learning styles. Some researchers regarded learning as a step-by-step activities, and a student's behaves could vary in each step, leading to a set of combinations. Other researchers regarded learning as a whole process, thinking that a learner would show a typical learning preferences during the whole learning activity. Another kind of classification of learning styles was to ascribe the differences to different subjects.

Based on learning style theories and their measures, empirical researches showed a positive effect for a match between learning styles and teaching approaches (Peacock, 2001), indicating a possible application in pedagogical practices. However, early attempts on operationalizing learning style were problematic, due to a high rate failure for learning style identification (Curry\& Adams, 1991)). Some learning style models, like ATI and VAK, were proved to have a high matching effectiveness (Sen\& Yilmaz, 2012) but failed in another scenario (Riener\& Willingham, 2010). Researchers have to check the validity of Learning Style measures even with previous validation work, constructing a barriers in the model specification. Choosing the right model in the application is still a challenge in the field.

Table 1. Comparison of Main Learning Style Theories

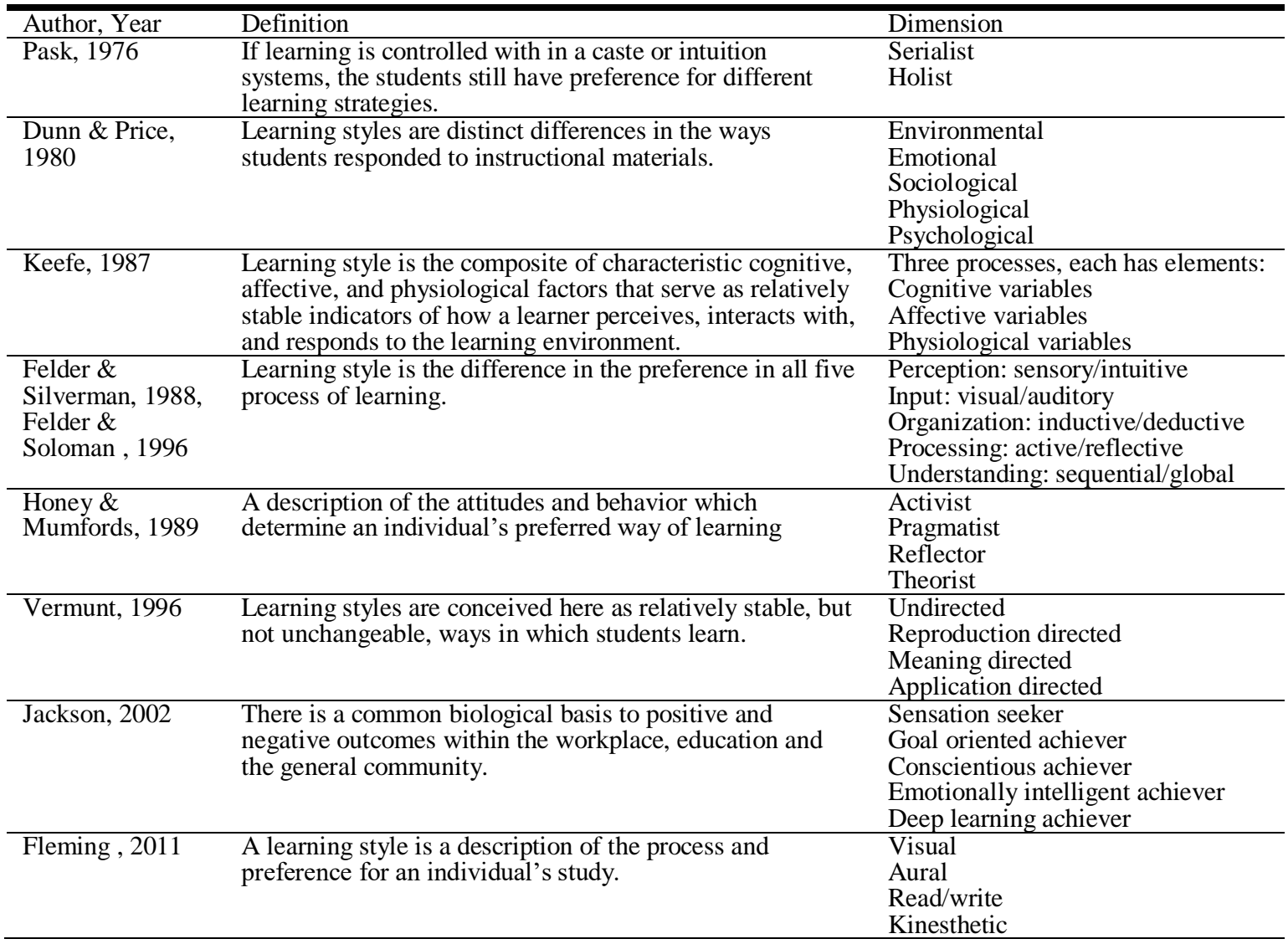




\subsection{Adaptive Hypermedia Learning System}

The conception of hypermedia was first introduced on 1965 by Ted Nelson (McAleese \& Green, 1990). This type of media includes a set of multisensory nonlinear information, including media (graphs, audio, video, text, etc.) and hyperlinks. Most of the early hypermedia were static, providing same information in a same sequence for all audiences, and hyperlink only provided the function of catalogues. With the development of technology and popularity among users, researchers turned to find some media system more adaptive to create a better usage experience. Due to the trait of nonlinear, hypermedia can provide information in a same theme with difference sequences for different audiences, and became a new direction for hypermedia design since 1990s (Yusob, Haron, Ahmad\& Halim, 1999).

Nearly at the same time came early exploration of using adaptive hypermedia in the area of education. Beumont and Bruilovsky first designed an adaptive hypermedia tutoring system using conditional presentation technique, which categorized audiences into two previous knowledge level, beginner and advanced. This system was just a conceptual model with no empirical users' feedback, but it began the era of introducing adaptive hypermedia system into education context. From then on, adaptive hypermedia learning systems were designed with different adaptors, including individual-related variables like personality (Yusob, Haron, Ahmad \& Halim, 1999) and gender (Caglayan, et al., 1997), and learning-related variables like user's motivation (Specht\& Oppermann, 1998) and education level (da Silva, Van Durm, Duval\& Olivié, 1998). With the introducing of different new adaptors, an increasing numbers of researchers used experimental design to assess whether these adaptors effective or not, and many studies found AHSL had a positive effect on students' academic performance (Truong, 2016) (Brusilovsky\& Millán, 2007).

\subsection{Learning Style Theory and Adaptive Hypermedia Learning System}

The early attempt to adapted students' learning styles in AHLS was in 1990s. In 1996, Carver et al. designed a hypermedia system adaptive to student's learning styles, which is considered to be an early attempt of hypermedia learning system adapting to learning styles (Carver, Howard\& Lavelle, 1996). In this research, Carver used the Felder-Silverman Index of Learning Style to categorize learners into different learning styles, and then provided them with some prepared learning materials according to their learning styles. Studies focused on AHLS using learning styles mostly used a similar pattern in the following year, first matching students with typical learning styles and then giving them different teaching instructions and materials. Most studies used more than one adaptors, to serve as a supplement for Learning Style adaptors (e.g. prior knowledge, learning motivations), since some researchers claimed that specific learning style adaption itself had no significant impact on the learners performance partly because of the personalization of AHLS needed more information (Mulwa, et al., 2010). However, as a contrary, those studies who only used learning styles as an indicators also showed a significant positive AHLS, comparing with the traditional classroom learning (Truong, 2016). The effectiveness of learning style adaptors is worth to further explore, both for single adaptor systems as well as those with multiple ones.

\section{RESEARCH QUESTION}

Although there are already many educational experiments assessed the effect of AHLS, considering the different environment and measurement of each study, a general effect size is still worth to compute. Plus, there might also be other potential factors that could affect the efficacy of AHLS. Learning style theory selection was considered to be an essential step in AHLS construction (Akbulut\& Cardak, 2012), and the additional adaptor was widely accepted to be a method to improve the performance of AHLS (Mulwa, 2010), which were also addressed above.

Thus, the research question of this study are listed below:

1) In general situation, to what extent that AHLS could help student increase its academic performance?

2) Would the two potential factor, Learning Style Theory choosing and Additional Adaptor, influence the effect of AHLS or not? If yes, influence by how much degree? 


\section{METHOD}

\subsection{Studies Searching and Selection}

Adaptive learning system researches first started in 1990s, but only got widely used and researched after 2000, partly due to the popularity of personal computers and smart phones (Mulwa, et al., 2011). Thus, 2000 was set as the start of studies collection, which is similar to many recent literature review in the field of educational technology. Articles published between 2000 January 1 to 2019 June 3 were included.

The data searching strategy used in this research was set according to Cooper \& Hedges' study on research synthesis (Cooper, Hedges \& Valentine, 2009). According to their view, studies searching for the purpose of research synthesis should be held in a broad range, but stressed more on precision rather than a high recall rate, using multiple databases related to the topic area, thus need more key words to form keyword combinations either or both restricted context, object, method etc.. For this study, the searching databases included: Emerald, JSTOR, SpringerLink, ScienceDirect, Wiley Online Library, Taylor\& Francis Online, EBSCOhost and ProQuest. First keyword set comes from the context, to restrict the topic into the educational technology topic, including "e-learning", "educational hypermedia", "leaning/tutoring system", "computer/web/mobile assisted/based learning"; second keyword set comes from the aim of adaptation of the system, including "adaptive", "adaptable", "adaptivity", "adaptability", "adaptation", "personalized"; the third keyword to limited the way of adaptation into learning style, including "learning/cognitive style"; the fourth keyword set was used to filtrate those studies who conducted experimental design to evaluate the efficiency of the system, rather than just simply created a system, including "evaluation", "measurement", "experiment(al)" "control group". Articles only included peer reviewed journal paper, conference proceedings for full paper, and dissertation for master or $\mathrm{PhD}$. Degrees.

The primary attempt gave 178 recalls. Then selection focused on four detailed points: 1) this is an adaptive hypermedia learning system, using hypermedia as learning materials and adapted by learner's traits; 2) at least one of the adaptor is learning style; 3) the research conduct a control experiment to compare the mean difference of learning effectiveness for experimental and control groups; 4) the study give the mean, standard deviation and sample size for both control group and experimental group. After the third round selection, 16 studies were selected for further analysis, 10 were peer-reviewed journal papers, 2 were conference proceeding full papers, 1 were doctoral dissertation. All the studies included 731 students in total.

\subsection{Data Extraction and Effect Size}

Information was extracted from these 13 papers under three steps. First was background information, including 1) the year of publication and the name of author, which was used to identify each paper; and 2) learning content, which was used to see the subjects that AHLS had been conducted in. These two variables were not necessary in the meta-analysis conducting, but still useful to see the overall trend of AHLS empirical researches in recent years.

The second part is about the sample information, including 1) sample size in each studies, 2) participants' information. The sample size was varied among studies, but the participants mostly were university students. The reason for this might be the available of participants, and AHLS were also mostly used on the higher education in actual application (Akbulut\& Cardak, 2012).

The third part is about the research design and AHLS design, including 1) Learning Style theory, 2) Additional Adaptor. Both were covariate in this study, whose importance have been discussed above. The variable of Learning Style Theory was coded as 1 and 0, which referred to using Felder \& Silverman's learning style theory or not. The reason of focusing on this theory is that more than half of all the studies using Felder \& Silverman's leaning style theory, without stating a solid reason on learning style theory choosing, ignoring that Felder proclaimed they formed and validated this theory in the engineer education. To assess the rationality of simply using Felder's Theory without Learning Theory screening, two groups, using or not using Felder $\&$ Silverman's Theory were thus compared. The variable of Additional Adaptor were coded also as 1 and 0 , for adapting or not adapting additional adaptor, to see whether adapting an additional adaptor could benefit to the effect of AHLS. 
Since each study used different test and mark system to assess student's academic performance, all the raw mean differences were transferred into standardized effect sizes. A widely accepted standardized effect size for mean difference is hedge's g, since it can standardize a raw mean differences across different samples and studies. Comparing another standardized mean difference, cohen's d, the hedge's g can fix some bias when sample sizes were small, which could be applied in this research as some selected studies had a relative small sample (Borenstein, Hedges, Higgins\& Rothstein, 2011).

\section{RESULT AND DISCUSSION}

\subsection{The Overall Effect of Learning Style AHLS}

According to the result of meta-analysis, there was a significant differences in the academic performance, which presented by final score in all the studies, between control group and experiment group. There showed an evidence for heterogeneity across all the studies $\left(\mathrm{I}^{2}=54.26 \% ; p=0.009\right)$, validating a proposal of a random effects model. The funnel plot showed a possibility of publication bias in this study, but the test of publication bias show no evidence on that (Funnel Plot Asymmetry $\mathrm{Z}=-0.754, p=0.451$ ).

The model result showed a significant positive effect of AHLS on students' academic performance $(0.606$, $\mathrm{p}<0.001$ ), which is consistent to most of the previous research. All the estimate of this model are showed in the below table as Model 0 .
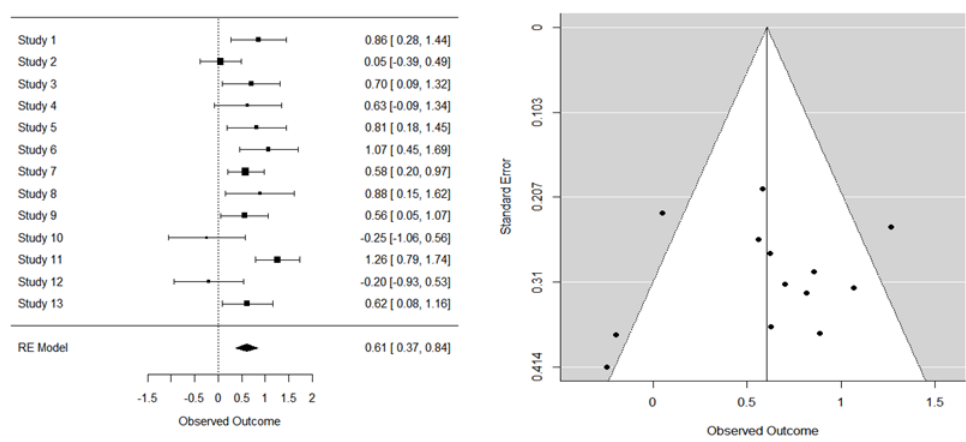

Figure 1. Forest plot and Funnel Plot of Model 0

\subsection{The Effect of Meta-Regression}

For the research question 2, to assess the effect of Learning Style Theory choosing, three additional meta-analysis model were specified. The first one is Model 1, adding Learning Style Theory as a covariate, named as Model 1. Results showed no evidence of a moderating effect of Learning Style Theory to the AHLS positive effect on students' learning performance, and the increasement of tau-squared seems to not support the decision of including Learning Style Theory into the model $\left(\operatorname{tau}^{2}=0.100\right.$, $\left.\mathrm{se}=0.080\right)$, with an decrease in $\mathrm{I}^{2}\left(\mathrm{I}^{2}=53.95 \%\right)$. This result showed that the Learning Style choosing has a non-significant negative moderate effect on the AHLS's positive effect $(-0.160, p=0.513)$.

Model 2 added Additional Adaptor as a covariate comparing to Model 0, showing that Additional Adaptor non-significantly negatively moderated the effect of $\operatorname{AHLS}(0.127, p=0.633)$. The increase in tau-squared, however, inferred that this covariate should be included, with an relatively bigger increase for $\mathrm{I}^{2}\left(\mathrm{I}^{2}=57.65 \%\right.$, $\operatorname{tau}^{2}=0.116$, se $\left.=0.088\right)$. Even though including the moderator of Learning Style seems to increase between-study variation, the amount accounted for by the random effect model can (relatively) go down, thus showing the moderator still works for the model.

Model 3 add both Learning Style Theory and Additional Adaptor into the model, to see whether the two moderator would influence the model together or not. This model also showed an increasement in tau-squared $\left(\operatorname{tau}^{2}=0.117\right.$, se $\left.=0.093\right)$, but a decrease in $\mathrm{I}^{2}$ comparing with the baseline model $\left(\mathrm{I}^{2}=57.10 \%\right)$. These 
parameters seems to be not a big different with the model 2, and thus a parsimonious principle should be considered here, indicating the Model 2 should be the most acceptable one. The estimations were showed as Table 3. Figure 2 was the forest plot and funnel plot for the final chosen model, Model 2.

Adding adaptors was considered to be useful way to increase the effectiveness of AHLS in many researchers (Mulwa, et al., 2010), but the evidence of the study showed that it is not as effective as they said. Comparing with the effect brought by the Learning Style AHLS, the additional adaptor's positive effect was non-significant, making no statistically different on the positive effect of Learning Style AHLS. Considering the desire of less complexity in user model specification and the system construction, it might be better to limit the behavior of adding adaptor, as it not play an essential role for the final effectiveness of AHLS.
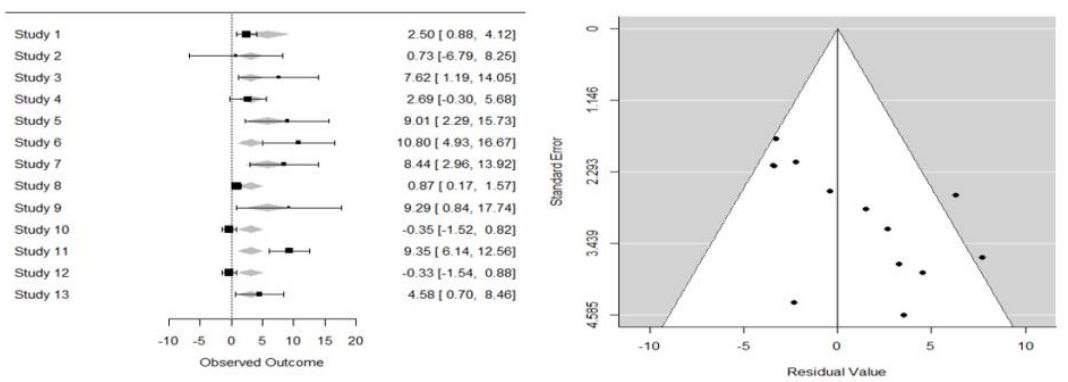

Figure 2. Forest plot and Funnel Plot of Model 3

Table 2. Summary of Model 0, 1, 2, 3

\begin{tabular}{|c|c|c|c|c|}
\hline & Model 0 & Model 1 & Model 2 & Model 3 \\
\hline \multicolumn{5}{|c|}{ Estimates of model diagnostic } \\
\hline $\mathrm{I}^{\wedge} 2$ & $54.26 \%$ & $53.95 \%$ & $57.65 \%$ & $57.10 \%$ \\
\hline QE & $26.235(p=0.009)$ & $23.886(p=0.013)$ & $25.973(p=0.007)$ & $23.309(p=0.010)$ \\
\hline $\mathrm{H}^{\wedge} 2$ & $2.19 \times$ & 2.17 & 2.36 & 2.33 \\
\hline $\mathrm{R}^{\wedge} 2$ & Not Applicable & $0.00 \%$ & $0.00 \%$ & $0.00 \%$ \\
\hline $\mathrm{Tau}^{\wedge} 2$ & $0.098(\mathrm{se}=0.076)$ & $0.100(\mathrm{se}=0.080)$ & $0.116(\mathrm{se}=0.088)$ & $0.117(\mathrm{se}=0.093)$ \\
\hline \multicolumn{5}{|c|}{ Estimates of variables } \\
\hline AHLS & $\begin{array}{l}0.606(\mathrm{se}=0.120), \\
\mathrm{p}<0.001\end{array}$ & $\begin{array}{l}0.673(\mathrm{se}=0.159), \\
\mathrm{p}<0.001\end{array}$ & $\begin{array}{l}0.562(\mathrm{se}=0.155) \\
\mathrm{p}<0.001\end{array}$ & $\begin{array}{l}0.626(\mathrm{se}=0.182) \\
p=0.001\end{array}$ \\
\hline $\begin{array}{c}\text { LS } \\
\text { Theory }\end{array}$ & & $\begin{array}{l}-0.160(\mathrm{se}=0.245) \\
p=0.513\end{array}$ & & $\begin{array}{l}-0.174(\mathrm{se}=0.259) \\
p=0.570\end{array}$ \\
\hline $\begin{array}{l}\text { Additional } \\
\text { Adaptor }\end{array}$ & & & $\begin{array}{l}0.127(\mathrm{se}=0.267) \\
p=0.633\end{array}$ & $\begin{array}{l}0.153(\mathrm{se}=0.270) \\
p=0.501\end{array}$ \\
\hline
\end{tabular}

\section{CONCLUSION}

This studies used 13 previous studies to see the general effectiveness of AHLS using Learning Style Theory, and then discuss the moderating effect of two factor, Learning Style Theory and Additional Adaptor. AHLS is effective among general subjects, and adding adaptor did not influence a lot on that positive effect. In the application of AHLS under the classroom context, adding more adaptor would not necessarily benefit to the performance of students, and once the adaptivity get applied, the more concern of system design and application should focus on other side instead of simply adding new adaptors.

However, this study still have several limitations. The first could be the number of studies. AHLS has a short history and thus a smaller number of studies comparing with other educational technology tools, and when the adaptor focus on Learning Style the number of studies could decrease more. Second limitation could be other potential covariates, like identification algorithm and student age, might also influence the effectiveness of AHLS, which is not discussed in this study. But with a scanty number of studies it is hard to get enough sample for each covariate. In recent years, more researchers and educators noticed the usefulness of AHLS and the importance of conducting empirical studies to see the effectiveness, and with these new emerging researches it could be possible to discuss these questions. 


\section{REFERENCES}

Akbulut, Y., \& Cardak, C. S. (2012). Adaptive educational hypermedia accommodating learning styles: A content analysis of publications from 2000 to 2011. Computers \& Education, 58(2), 835-842.

Akbulut, Y., \& Cardak, C. S. (2012). Adaptive educational hypermedia accommodating learning styles: A content analysis of publications from 2000 to 2011. Computers \& Education, 58(2), 835-842.

Borenstein, M., Hedges, L. V., Higgins, J. P., \& Rothstein, H. R. (2011). Introduction to meta-analysis. John Wiley \& Sons. pp 21-32.

Brusilovsky, P., \& Millán, E. (2007). User models for adaptive hypermedia and adaptive educational systems. In The adaptive web (pp. 3-53). Springer, Berlin, Heidelberg.

Caglayan, A., Snorrason, M., Jacoby, J., Mazzu, J., Jones, R., \& Kumar, K. (1997). Learn sesame a learning agent engine. Applied Artificial Intelligence, 11(5), 393-412.

Carver Jr, C. A., Howard, R. A., \& Lavelle, E. (1996, June). Enhancing student learning by incorporating learning styles into adaptive hypermedia. In EdMedia+ Innovate Learning (pp. 28-32). Association for the Advancement of Computing in Education (AACE).

Carver, C. A., Howard, R. A., \& Lane, W. D. (1999). Enhancing student learning through hypermedia courseware and incorporation of student learning styles. IEEE transactions on Education, 42(1), 33-38.

Chen, S. Y., \& Macredie, R. D. (2002). Cognitive styles and hypermedia navigation: Development of a learning model. Journal of the American society for information science and technology, 53(1), 3-15.

Cooper, H., Hedges, L. V., \& Valentine, J. C. (Eds.). (2009). The handbook of research synthesis and meta-analysis. Russell Sage Foundation. pp 71-77.

Curry, L., \& Adams, C. (1991). Patterns of learning style across selected medical specialties. Educational psychology, 11(3-4), 247-277.

da Silva, D. P., Van Durm, R., Duval, E., \& Olivié, H. (1998, June). Concepts and documents for adaptive educational hypermedia: a model and a prototype. In Second workshop on Adaptive Hypertext and Hypermedia, Ninth ACM Conference on Hypertext and Hypermedia, Pittsburgh, USA (pp. 35-43).

Dunn, R. S., \& Price, G. E. (1980). The learning style characteristics of gifted students. Gifted Child Quarterly, 24(1), 33-36.

Felder, R. M. (1996). Matters of style. ASEE prism, 6(4), 18-23.

Felder, R. M., \& Silverman, L. K. (1988). Learning and teaching styles in engineering education. Engineering education, 78(7), 674-681.

Fleming, S., Mckee, G., \& Huntley-Moore, S. (2011). Undergraduate nursing students' learning styles: A longitudinal study. Nurse education today, 31(5), 444-449.

Honey, P., \& Mumford, A. (1989). Learning styles questionnaire. Organization Design and Development, Incorporated. pp 324-336.

Jackson, C. J. (2002). Predicting team performance from a learning process model. Journal of Managerial Psychology, 17(1), 6-13.

Jonassen, D. H., \& Grabinger, R. S. (1990). Problems and issues in designing hypertext/hypermedia for learning. In Designing hypermedia for learning (pp. 3-25). Springer, Berlin, Heidelberg

Kahraman, H. T., et al. (2010, October). Development of adaptive and intelligent web-based educational systems. In 2010 4th International Conference on Application of Information and Communication Technologies (pp. 1-5).

Kazu, I. Y. (2009). The effect of learning styles on education and the teaching process. Journal of Social Sciences, 5(2), 85-94.

Keefe, J. W. (1982). Student learning styles and brain behavior: Programs, instrumentation, research. Reston, VA: National Association of Secondary School Principals. pp 148-197.

Klašnja-Milićević, A., Vesin, B., Ivanović, M., \& Budimac, Z. (2011). E-Learning personalization based on hybrid recommendation strategy and learning style identification. Computers \& Education, 56(3), 885-899.

Linn, M. (2003). Technology and science education: Starting points, research programs, and trends. International journal of science education, 25(6), 727-758.

McAleese, R., \& Green, C. (Eds.). (1990). Hypertext: state of the art. Intellect Books. pp 10-20.

Mulwa, C., Lawless, S., Sharp, M., \& Wade, V. (2011, August). A web-based framework for user-centred evaluation of end-user experience in adaptive and personalized e-learning systems. In 2011 IEEE/WIC/ACM International Conferences on Web Intelligence and Intelligent Agent Technology (Vol. 3, pp. 351-356). IEEE. 
Mulwa, C., Lawless, S., Sharp, M., Arnedillo-Sanchez, I., \& Wade, V. (2010, October). Adaptive educational hypermedia systems in technology enhanced learning: a literature review. In Proceedings of the 2010 ACM conference on Information technology education (pp. 73-84). ACM.

Mulwa, C., Lawless, S., Sharp, M., Arnedillo-Sanchez, I., \& Wade, V. (2010, October). Adaptive educational hypermedia systems in technology enhanced learning: a literature review. In Proceedings of the 2010 ACM conference on Information technology education (pp. 73-84). ACM.

Mulwa, C., Lawless, S., Sharp, M., Arnedillo-Sanchez, I., \& Wade, V. (2010, October). Adaptive educational hypermedia systems in technology enhanced learning: a literature review. In Proceedings of the 2010 ACM conference on Information technology education ( $\mathrm{pp}$. 73-84).

Nelson, B., Dunn, R., Griggs, S. A., \& Primavera, L. (1993). Effects of learning style intervention on college students retention and achievement. Journal of College Student Development. 34(5), 364-369.

Pask, G. (1976). Styles and strategies of learning. British journal of educational psychology, 46(2), 128-148.

Peacock, M. (2001). Match or mismatch? Learning styles and teaching styles in EFL. International Journal of Applied Linguistics, 11(1), 1-20.

Riener, C., \& Willingham, D. (2010). The myth of learning styles. Change: The magazine of higher learning, 42(5), 32-35.

Sen, S., \& Yilmaz, A. (2012). The effect of learning styles on student's misconceptions and selfefficacy for learning and performance. Procedia-Social and Behavioral Sciences, 46, 1482-1486.

Specht, M., \& Oppermann, R. (1998). ACE-adaptive courseware environment. New Review of Hypermedia and Multimedia, 4(1), 141-161.

Tolhurst, D. (1995). Hypertext, hypermedia, multimedia defined? Educational Technology, 35(2), 21-26.

Truong, H. M. (2016). Integrating learning styles and adaptive e-learning system: Current developments, problems and opportunities. Computers in human behavior, 55, 1185-1193.

Vermunt, J. D. (1996). Metacognitive, cognitive and affective aspects of learning styles and strategies: A phenomenographic analysis. Higher education, 31(1), 25-50.

Yusob, B., Haron, N., Ahmad, N. B. H., \& Halim, S. A. (1999). Individualizing the learning material and navigation path in an adaptive hypermedia learning system. In Proceedings of the International Joint Conference on Neural Network (pp. 3517-3521). 